\title{
DAMPAK FINANCIAL QUOTIENT DAN LIFESTYLE TERHADAP FINANCIAL BEHAVIOR DOSEN WANITA DI STIE PANCASETIA BANJARMASIN
}

\author{
Melania ${ }^{1)}$ \\ Sekolah Tinggi Ilmu Ekonomi Pancasetia Banjarmasin, Indonesia \\ melaniasjachrani@yahoo.com \\ Tri Ratnawati ${ }^{2)}$ \\ Faculty Economy and Business, University of 17 Agustus 1945 Surabaya, Indonesia \\ tri.wdhidayat@yahoo.com \\ Anthonius J Karsudjono ${ }^{3)}$ \\ Sekolah Tinggi Ilmu Ekonomi Pancasetia Banjarmasin, Indonesia \\ tonimbbm@yahoo.com
}

\begin{abstract}
Financial behavior is a reflection of human behavior in managing their finances, many things that can affect, including financial quotient and lifestyles. The aim of the study is to understand the impact of financial quotient and lifestyles on financial behavior of female lecturers at STIE Pancasetia Banjarmasin. Data was collected through indepthinterview with three resource persons who teach finance or e-commerce. Understanding financial does not necessarily make a person implement it comprehensively in life, especially for female workers who are relatively young, there is a tendency not to pay attention to risks and protection for their future. Today's lifestyle is closely related to the nurture, and this can be seen from their habits in using money. Individuals with better financial quotient will better understand how to plan the utilization of their income so they will choose a lifestyle that suits them, so they will behave in accordance with these choices.
\end{abstract}

Key words: Financial Behavior, Financial Quotient, Lifestyles, Female 


\section{PENDAHULUAN}

Pengetahuan finansial dikenal melalui banyak istilah yang sering dipertukarkan penggunaannya, ada yang menyebutnya financial literacy, financial knowledge, financial education, financial quotient $(F Q)$. Semua istilah ini menggambarkan hal yang serupa, yaitu kemampuan dalam mengelola keuangan. Pengetahuan finansial sangat penting karena dengan menerapkan cara pengelolaan keuangan yang benar, maka seseorang bisa mendapatkan manfaat yang maksimal dari uang yang dimilikinya. Sebagai pelaku usaha industri kecil misalnya, financial literacy merupakan salah satu kekuatan untuk meningkatkan produktifitas (Ratnawati et al., 2017), keterbatasan pemahaman mengenai keuangan ini membuat $F Q$ tidak berpengaruh secara signifikan terhadap kinerja wirausaha (Mujanah et al., 2019). Sebagai individu, financial literacy juga penting, karena berkaitan erat dengan proses manajemen serta pengalokasian keuangan yang dimilikinya. Pengetahuan akan membuat banyak perbedaan antara kesuksesan dan kegagalan finansial.

Seseorang dengan $F Q$ tinggi dipercaya memiliki financial behavior lebih baik dan dapat membuat keputusan finansial yang bagus, dan sejalan dengan lingkungan ekonomi yang ada maka dia akan memperoleh dampak finansial yang lebih bagus pula (Andarsari \& Ningtyas, 2019; Nobriyanni \& Haryono, 2019; Robb \& Woodyard, 2011; Halimatussakdiyah et al., 2019).

Berbeda dengan hasil penelitian tersebut, penelitian Herdjiono \& Damanik (2016) menunjukkan bahwa financial knowledge tidak berpengaruh signifikan terhadap financial behavior karena kurang efektifnya financial education di wilayah atau negara berpendapatan menengah ke bawah, demikian pula temuan Borden et al.,(2008), Kholilah \& Iramani (2013), Nano, (2015), Hilgert et al., (2003).

Penelitian ini bertujuan untuk memahami dampak $F Q$ dan Lifestyles terhadap Financial Behavior dosen wanita di STIE Pancasetia Banjarmasin. 


\section{TINJAUAN PUSTAKA}

\section{Manajemen Keuangan Keluarga}

Keluarga atau rumah tangga adalah sekelompok individu yang pengambilan keputusan ekonominya saling terkait. (household. (n.d.) Collins Dictionary of Economics, 2020). Belanja apapun merupakan keputusan finansial dan segala hal yang berpotensi untuk merubah situasi finansial konsumen ini, bersumber dari karakteristik personal, keahlian dan kebiasaan (Lynch, 2011).

Proses keputusan finansial yang penting meliputi keputusan berinvestasi, asuransi, tabungan dan waktu pensiun (Skals, 2020). Mengelola keuangan keluarga menurut Safir Senduk harus banyak berinvestasi, baik itu dalam bentuk emas, reksa dana, atau menabung, selain investasi juga perlu menyiapkan dana untuk masa depan, dan yang tidak kalah penting adalah mengatur pengeluaran (Lestari, 2016).

\section{Financial Behavior}

Perilaku dalam keuangan didasarkan pada premis bahwa manusia seringkali irasional atau kuasirasional, dan individu membuat keputusan finansial berdasarkan pada pengalamannya, nilai, kesalahan mental, faktor kognitif, dan dorongan emosional (Baker et al., 2017). Ketika individu membuat penilaian, mereka mencari, mengevaluasi, dan memilih diantara sekian banyak pilihan, keputusan akhir didasarkan pada tingkat resiko dan ketidak pastian, jadi financial behavior merefleksikan bagaimana perilaku manusia relevan dengan pengelolaan keuangan (Ricciardi, 2008; Xiao, 2009). Secara sederhana, financial behavior merujuk pada praktek pengelolaan finansial dari keahlian dasar mengelola uang sampai dengan aktifitas perencanaan keuangan yang canggih (Hilgert et al., 2003). Kholilah \& Iramani (2013) mengukur financial behavior dengan menggunakan empat indikator yaitu pembayaran tagihan tepat waktu, penyusunan rancangan keuangan untuk masa depan, penyisihan uang untuk tabungan, pembagian uang untuk keperluan pribadi dan keluarga. 


\section{Lifestyle}

Menurut (Young et al., 2010) lifestyle didasarkan pada pemikiran seseorang, keyakinan dan etika yang ada di masyarakat, yang berdampak signifikan terhadap keputusan yang diambil seseorang baik itu terkait dengan kehidupan personal maupun profesionalnya. Keputusan, dengan demikian, dipengaruhi oleh lifestyle seseorang.

Penelitian mengenai lifestyle mengukur aktivitas manusia melalui bagaimana mereka menghabiskan waktunya; apa yang membuat mereka tertarik dan apa yang penting bagi mereka dalam waktu dekat; pandangan mereka atas diri mereka sendiri dan lingkungannya; dan beberapa karakteristik demografi (Khraim, 2015; Sharma \& Lal, 2012). Fraj \& Martinez (2006) dan He et al., (2010) menggunakan lima dimensi untuk memahami lifestyle yaitu need for uniqueness, didefinisikan sebagai sikap mengejar perbedaan relatif dengan orang lain melalui perolehan, pemanfaatan dan disposisi consumer goods dengan tujuan mengembangkan dan meningkatkan citra sosial dan citra diri (Tian et al., 2001); price consciousness, konsumen cenderung berbelanja produk umum yang harganya lebih murah sebagai pilihan gaya hidupnya (Todd \& Lawson, 2003); public interest orientation, salah satu konsep yang paling berpengaruh terhadap hubungan manusia dengan alam adalah kerinduan untuk menyatu dengan alam (Sholz, 2012); need for achievement, merupakan penentu perilaku konsumen yang berkelanjutan (Vermeir \& Verbeke, 2008); dan need for respect, menekankan pada aspek pentingnya identitas diri untuk melambangkan kebebasan (Niinimaki, 2010; Ishawini \& Datta, 2011)

\section{Financial Quotient (FQ)}

Penggunaan istilah Financial Literacy, Financial Knowledge, dan financial education sering kali dipakai untuk menggambarkan hal yang sama dalam literatur ilmiah maupun media populer (Huston, 2010). Financial Literacy didefinisikan sebagai financial knowledge (Hilgert et al., 2003). Menurut Vitt et al., (2000) Financial Literacy adalah 
kemampuan membaca, menganalisa, mengatur dan mengomunikasikan mengenai kondisi finansial seseorang yang memengaruhi kesejahteraan material. Merangkum berbagai definisi yang ada, Hung et al., (2009), memberikan konsep financial literacy sebagai pengetahuan ekonomi dasar dan konsep keuangan, sebagai kemampuan untuk menggunakan pengetahuan dan keahlian finansial lainnya dalam mengelola sumber keuangan secara efektif untuk kesejahteraan finansial. Secara konseptual, Huston (2010), financial literacy memiliki dua dimensi yaitu memahami (pengetahuan finansial individu) dan menggunakan (penerapan finansial individu).

Financial quotient (FQ) adalah kesadaran akan kondisi keuangan dan kemampuan seseorang dalam memahami pentingnya perencanaan keuangan dan mengimplementasikan tata kelola keuangan dengan baik. $F Q$ diderivasi dari istilah $I Q$. Kesejahteraan finansial merupakan konsekuensi dari keputusan finansial baik itu bernilai besar maupun kecil. Tingginya tingkat $F Q$ seseorang dapat diperoleh dari pendidikan (IDA, 2020). Hasil penelitian (Chinen \& Endo, 2012) memperlihatkan bahwa sikap ekonomis, status ekonomi mempengaruhi financial literacy, yang kemudian berpengaruh terhadap financial behavior. Hal ini sejalan dengan hasil yang diperoleh Atkinson \& Messy (2012) bahwa financial literacy berpengaruh positif terhadap financial behavior, dengan mempertimbangkan bahwa knowledge direpresentasikan sebagai semua informasi yang dimiliki oleh seseorang, bahkan banyak literature yang mengindikasikan adanya hubungan antara financial knowledge dan beberapa perilaku ekonomis, tidak hanya financial behavior (Lusardi \& Mitchell, 2014; Rooij et al., 2012; Garber \& Koyama, 2016)

\section{METODE PENELITIAN}

Metode yang digunakan dalam penelitian ini adalah kualitatif studi kasus, dengan tiga informan yang merupakan dosen wanita dan pengajar mata kuliah yang terkait dengan keuangan atau e-commerce di STIE Pancasetia Banjarmasin. Penelitian 
dilaksanakan pada bulan Februari-April 2020. In-depth interview dilakukan melalui telepon dan internet chatting.

FQ dieksplorasi atas enam dimensi dengan mengadopsi model yang dikembangkan oleh Cindy Yu \& Hong Zhang. Lifestyle dieksplorasi dari lima dimensi mengadopsi dari Fraj \& Martinez, 2006; dan He et al., (2010). Financial behavior diekplorasi atas empat dimensi, diadopsi dari Kholilah \& Iramani (2013). Langkahlangkah yang dilakukan dalam penelitian ini: (1) mengindentifikasi fenomena; (2) mengidentifikasi partisipan; (3) mengumpulkan data; (4) menganalisa data; (5) interpretasi, penarikan kesimpulan atas temuan penelitian. Menjaga kredibilitas data, peneliti melakukan triangulasi, baik terhadap sumber, metode, waktu maupun teori.

\section{HASIL PENELITIAN DAN PEMBAHASAN}

\section{Financial Quotient}

Mengenai $F Q$ dalam hal perencanaan, semua informan ada perencanaan keuangan karena amat memahami biaya yang dibutuhkan dan penghasilan yang diterima. "sudah ada pos belanja rutin bulanan, terencana, tetapi tidak menutup kemungkinan diluar itu, biasanya di awal bulan sudah disiapkan" (informan A, 33 tahun); "jadi harus mencari back up apabila mengalami kekurangan tanpa harus berhutang. Sudah membagi-bagi pendapatan untuk biaya rutin (informan B, 34 tahun); "saya tidak pernah menghitung berapa pengeluaran saya per bulan, tetapi saya tipe orang yang tidak mau menghabiskan uang, harus punya tabungan" (informan C, 33 tahun). Mengenai kredit dan utang, informan A dan C tidak memiliki utang ke pihak manapun, tidak berminat memiliki kartu kredit yang biasanya memungkinkan penggunanya untuk berhutang; sedangkan informan B ada kredit rumah, dan menghidari penggunaan kartu kredit walaupun memilikinya. 
Karir dan pendapatan, informan A "untuk biaya hidup sudah mencukupi, karena berkarir sebagai dosen ya akan terus meningkatkan kepangkatan, ada target untuk sekolah Doktor". "Penghasilan tahunan tidak diduga sebesar yang ada, karena ada pendapatan diluar gaji yang ternyata sangat membantu, dari sisi karir dosen, amat paham akan ke arah mana, karena sudah terstruktur, tinggal kita aja mau atau tidak" (informan B). "Jujur, karir yang ada sekarang sebagai dosen bukan tujuan hidup saya" (informan C). Informan A berinvestasi dalam bentuk reksa dana, informan B lebih beragam yaitu investasi rumah, tanah, asuransi + investasi, joint usaha dengan teman. Informan $\mathrm{C}$ berinvestasi ke perhiasan emas dan menabung di bank, sedangkan pendapatan keluarga /suami ke properti.

Berkenaan dengan perencanaan finansial, informan A sudah membuat perencanaan yang diwujudkan melalui membuat pos pos supaya teratur pengeluaran, kalau ada kelebihan ditabung berupa reksa dana. Informan B mengatakan "menabung bukan prioritas, lebih ke investasi dan asuransi link untuk masa depan". Informan C mengatakan "dari gaji saya pribadi, ada uang yang dipakai untuk kebutuhan seharihari, dan selalu ada pos untuk ditabung". Terkait dengan resiko dan proteksi, informan A memiliki (program kampus) asuransi jiwa, kesehatan, dan masa tua, serta secara pribadi mempersiapkan dana untuk pendidikan anak; informan B "punya (program kampus) asuransi jiwa-kesehatan, dan juga memiliki asuransi rumah. Saya memahami mengenai pentingnya memiliki cadangan dana untuk kondisi darurat, karena itu walaupun tidak dimanfaatkan tetapi masih mengaktifkan kartu kredit"; informan C "diluar program kampus saya tidak punya asuransi lain".

Memahami mengenai hal-hal terkait finansial ternyata tidak serta merta membuat seseorang mengimplementasikannya secara menyeluruh dalam kehidupan, khususnya bagi mereka yang berusia relatif muda ada tendensi untuk tidak terlalu memperhatikan resiko dan proteksi untuk masa depan mereka. 


\section{Lifestyle}

Terkait dengan need for uniqueness informan memberikan jawaban yang beragam, "Saya suka bereksperimen menggunakan cara yang baru dalam mengerjakan sesuatu, dalam belanja misalnya, biasanya nyoba aplikasi pembayaran baru karena ada keuntungan misalnya berupa diskon. Jadi saya tidak selalu mengikuti aturan yang ada, sering mencari jalan atau metode berbeda. Saya menikmati menjadi trendsetter. Saya suka sekali mengambil peluang, apalagi kalau itu adalah peluang diskon. Saya senang bertualang dalam hal mencoba sesuatu yang baru, dan suka juga keluar dari kegiatan rutin sehari-hari, misalnya tidak langsung pulang ke rumah dari tempat kerja, tergantung mood" (informan A). "Bereksperimen jarang saya lakukan, kalau ada planning yang jelas baru melakukan ekperimen, misal mau membeli sesuatu, membandingkan berbagai macam produk/merk/model/toko melalui IG, market place misal toped dan shopee. di market place itu ada tanda bintang untuk best seller, misal bintang lima untuk produk dan respon toko, akan dicek produk disitu, liat stok barang, baca komentar baru order. Order dilakukan setelah merasa yakin/aman. Pembayaran biasanya transfer langsung ke toped/shopee. Alhamdulillah selama berbelanja online saya tidak pernah dikecewakan, karena memperhatikan bintang dan komentar tadi. Untuk kebutuhan makanan masih bisa ke lokasi, tapi juga sering memanfaatkan fasilitas online. Saya cenderung selalu berupaya mengikuti aturan yang ada tetapi bisa saja mencari alternatif untuk memudahkan pelaksanaan. Kalau ada kegiatan yang menantang, saya suka mencabarnya, walaupun belum tahu hasilnya akan bagaimana. Saya suka sekali bertualang ke tempat-tempat terpencil, sejauh saya merasa aman saya akan melakukan itu. Saya menikmati me time dengan jalan jalan bersama teman, makan di luar" (informan B). Saya tidak suka bereksperimen, kalau ada aturan yang jelas saya akan mentaati aturan yang ada itu, apabila tidak bisa mencapai tujuan baru saya akan mencari cara yang berbeda. Saya tidak suka bertualang, tetapi kalau ada kesempatan 
untuk keluar dari aktifitas rutin, saya memanfaatkannya dengan jalan-jalan bersama teman-teman ke mall (informan C)

Terkait dengan price consciousness informan A dan B menyatakan mereka selalu mencari harga yang terbaik dengan cara membanding bandingkan di berbagai media, bisa ke ecommerce atau medsos. "Kalau belanja di supermarket, saya akan ngecek harga walaupun harga barang itu cuma seribuan" (informan B). Jawaban berbeda diberikan oleh informan C "saya tidak suka membandingkan harga barang, kalau memang sudah suka tidak akan membandingkan lagi dengan yang lain karena kalau banyak pilihan saya malah tidak bisa mengambil keputusan, terlebih lagi kalau barang itu amat saya butuhkan, saya akan langsung membeli yang pertama saya temui. Saya membeli merek yang sudah biasa dibeli walaupun ada yang lain dengan harga lebih murah, kecuali memang ada promo. Mengenai public interest orientation semua informan mengaku tidak terlalu bisa memperhatikannya, misal dalam hal kepedulian terhadap lingkungan, kerap kali tidak bisa berperan aktif karena situasi dan lebih memilih menyumbangkan sejumlah uang, meskipun semuanya menyadari pentingnya keharmonisan kehidupan manusia dengan alam untuk keberlanjutan kehidupan.

Need for achievement. Informan A dan C merasa termotivasi untuk berpretasi, sedangkan informan B merasa lebih ke untuk melakukan yang terbaik daripada memikirkan aku harus berprestasi tertentu, prestasi adalah bonusnya. Ketiganya merasa perlu untuk membuat perencanaan dan berjuang untuk mencapai tujuan. Informan A “jarang membuat list apa yang harus dilakukan tetapi lebih men-setting goalsnya, planning biasanya dinamis tergantung sikon yang dihadapi", berbeda dengan informan B dan C "ada list... semua harus dibereskan, akan mencari cara untuk menyelesaikan" Need for respect, semua informan tidak selalu merasa perlu menjadi yang paling hebat di antara teman-temannya, tetapi tetap harus memunculkan bahwa kita menghargai orang lain dengan tidak harus kehilangan jati diri kita, tidak harus dihormati oleh teman teman, 
tetapi tidak diremehkan (informan B). Informan A menjaga silaturahmi dalam lingkungan keluarga dan teman-teman biasanya karena azas kepentingan, sedangkan informan B dan C amat menghargai kehangatan dan ketulusan.

\section{Financial Behavior}

Pembayaran tagihan tepat waktu; tagihan rutin spt listrik, air, tepat waktu. menggunakan media e-commerce, dgn memanfaatkan diskon dan cash back (informan A), “bayar tagihan kredit rumah auto debet, tag listrik, air, telpon tepat waktu dengan memanfaatkan diskon atau cashback melalui point, marketplace. misal OVO ada cashback, poinnya dipakai utk belanja lagi secara online maupun offline" (informan B). Demikian pula informan C, selalu membayar tagihan rutinnya tepat waktu. Penyusunan rancangan keuangan untuk masa depan, informan A dan B memanfaatkan asuransi, baik yang diprogramkan di kampus maupun secara pribadi. "Saya tidak ada perencanaan keuangan khusus untuk masa depan" (informan C).

Penyisihan uang untuk tabungan, "saya menabung secara rutin melalui arisan, kalau ada lebih baru masuk tabungan, biasanya ada aja per bulannya" (informan A). “Tabungan melalui arisan karyawan. dana yang ada digunakan untuk berinvestasi di sektor riil" (informan B). "Saya selalu menyisihkan uang untuk menabung setiap bulannya" (informan C).

Pembagian uang untuk keperluan pribadi dan keluarga: "sudah diatur di awal bulan, sudah dicatat pos untuk segala macam kebutuhan yaitu untuk anak, sehari-hari dan pribadi, untuk pribadi biasanya untuk kosmetik. Kebutuhan suami sehari hari ditanggung dari penghasilan suami, seperti makan diluar dll" (informan A). “Dilakukan, untuk kebutuhan sehari hari, membantu pendidikan adik, kadang kadang ikut memenuhi kebutuhan sekunder dan tersier" (informan B). "Saya tidak membagibagi uang untuk keperluan pribadi dan keluarga, pendapatan keluarga digabung untuk dipakai bersama"' (informan C). 
Financial behavior yang diamati berusaha merekam bagaimana keteraturan dalam mengelola keuangan individu, baik itu untuk kebutuhan pribadinya maupun untuk kebutuhan keluarga, dan bagaimana seseorang mampu memanfaatkan peluang peluang finansial yang ada untuk mengoptimalkan sumber dana yang dimiliki.

Perilaku finansial pada dasarnya merupakan implementasi dari pemahaman individu akan pilihan-pilihan yang ada dalam kehidupannya yang bisa mempengaruhi keputusan finansial, dan pilihan yang diambilnya ini akan terlihat dari gaya hidup yang dianutnya. Individu dengan FQ baik sangat memahami bagaimana merencanakan pemanfaatan pendapatannya sehingga akan memilih gaya hidup yang sesuai dengan itu, dengan demikian akan berperilaku selaras dengan pilihannya tersebut. Secara empiris, hal ini ditunjukkan dari hasil penelitian Shih \& Ke (2013), Robb \& Woodyard (2011) bahwa financial literacy konsumen berhubungan positif dengan financial behavior mereka, juga hasil penelitian Sharma \& Lal (2012) dan Mohiuddin (2018) bahwa lifestyle mempengaruhi perilaku belanja kaum wanita.

\section{KESIMPULAN}

Terdapat kecenderungan pekerja wanita berusia muda tidak memperhatikan resiko dan proteksi untuk masa depan mereka sehingga hanya mengikuti program yang diadakan di lingkungan kerja, bisa jadi karena mereka merasa dapat mengandalkan orang lain, dalam hal ini adalah suami, untuk mencari nafkah. Mereka juga tidak terlalu bisa membagi waktu antara kegiatan di tempat kerja, keluarga dan kegiatan sosial terkait public interest orientation seperti lingkungan hidup, oleh karenanya lebih bersedia menggantikannya dalam bentuk sumbangan uang. Memahami mengenai finansial membuat kaum wanita lebih leluasa mengelola pendapatan pribadinya, diantaranya dengan memanfaatkan berbagai kemudahan yang ditawarkan oleh teknologi dalam berbelanja barang-barang dengan harga lebih murah 
tanpa kehilangan kualitas, atau memenuhi kewajiban pembayaran tagihan bulanan seperti listrik dan air secara tepat waktu.

\section{DAFTAR PUSTAKA}

Andarsari, P. R., \& Ningtyas., M. N. (2019). The Role of Financial Literacy on Financial Behavior. Journal on Accounting and Business Education, 4(1).

Atkinson, A., \& Messy, F.-A. (2012). Measuring Financial Literacy: Results of The OECD / International Network on Financial Education (INFE) Pilot Study. OECD Working Papers on Finance, Insurance and Private Pensions, 15.

Baker, H. K., Filbeck, G., \& Ricciardi, V. (2017). Financial Behavior: An Overview. In t. F. Series, Financial Behavior - Players, Services, Products, and Markets. Oxford University Press.

Borden, L. M., Lee, S. A., Serido, J., \& Collins, D. (2008). Changing college students' onancial knowledge, attitudes, and behavior through seminar participation. Journal of Economic Familly Issue, 29(1), 23-40.

Chinen, K., \& Endo, H. (2012). Effects of Attitude and Background on Personal Financial Ability: A Student Survey in the United States. International Journal of Management, 29(2), 778-791.

Dennis, C., Morgan, A., Wright, L., \& Jayawardhena, C. (2010). The Influence of Social e-shopping in Enhancing Young Women's Online Shopping Behavior. Journal of Customer Behavior, 9(2), 151-174.

Fraj, E., \& Martinez, E. (2006). Environmental Values And Lifestyles As Determining Factors Of Ecological Consumer Behaviour: An Empirical Analysis . Journal of consumer marketing, 23(3), 133-144.

Garber, G., \& Koyama, S. (2016). Policy-Effective Financial Knowledge and Attitude Factors. Working Paper Series.

Halimatussakdiyah, Martono, S., \& Sudarma, K. (2019). Influence of Life Style and Financial Literacy to Consumptive Behavior through Self-Control of Unisnu FEB College Students Jepara. Journal of Economic Education, $8(1), 75-80$. 
Handa, M., \& Khare, A. (2013). Gender as a Moderator of the Relationship between Materialism and Fashion Clothing Invovement among Indian Youth. International Journal of Consumen Studies, 112-120.

He, Y., Zou, D., \& Jin, L. (2010). Exploiting The Goldmine: A Lifestyle Analysis Of Affluent Chinese Consumers. Journal of consumer marketing, 27(7), 615-628.

Herdjiono, I., \& Damanik, L. A. (2016, Desember). Pengaruh Financial Attitude, Financial Knowledge, Parental Income Terhadap Financial Management Behavior. Jurnal Manajemen Teori dan Terapan, 9(3), 226241.

Hilgert, M. A., Hogarth, J. M., \& Beverly, S. G. (2003, July). Household Financial Management:The Connection between Knowledge and Behavior. Federal Reserve Bulletin, 309-322.

household. (n.d.) Collins Dictionary of Economics, 4. e. (2020, April 13). thefreedictionary.com. Retrieved April 14, 2020, from TheFreeDictionary: https://financial-dictionary.thefreedictionary.com/household

Hung, A. A., Parker, A. M., \& Yoong, J. K. (2009, September 23). Defining and Measuring Financial Literacy. Retrieved from http://www.rand.org.

Husnan, S. (2019). Pengertian dan Konsep-Konsep Dasar Keuangan. In S. Husnan, Modul Manajemen Keuangan. Jakarta: Universitas Terbuka.

Huston, S. J. (2010). Measuring Financial Literacy. The Journal of Consumer Affairs, 44(2), 296-316.

IDA. (2020, maret 29). IDA Wealth. Retrieved April 2, 2020, from Intelligence Driven Advisor: https://www.idawealth.com/iq-eq-and-the-financialquotient/

Ishawini, \& Datta, S. (2011). Pro-Environmental Concerns Influencing Green Buying: a Study on Indian Consumers. International Journal of Business and Management, 6, 124-133.

Kholilah, N. A., \& Iramani, R. (2013, May). Studi Financial Management Behavior pada Masyarakat Surabaya. Journal of Business and Banking, $3(1), 69-80$.

Khraim, H. S. (2015). Segmentation Of Young Consumers In Jordan In Terms Of Their Lifestyle: An Exploratory Study. American Journal of Business and Management, 4(1), 27-37. 
Lestari, M. R. (2016, Oktober 05). www.netralnews.com. (L. Eppang, Ed.) Retrieved April 12, 2020, from NETRALNEWS.COM : https://www.netralnews.com

Livingston, A. (2018). Men, Women \& Money - How the Sexes Differ With Their Finances. Retrieved April 1, 2020, from Money Crashers, LLC: https://www.moneycrashers.com/men-women-money-sexes-differfinances/

Lontoc, G. K. (2019, May 1). Applying The Financial Quotient Daily. Retrieved April 2, 2020, from BussinessMirror:

https://businessmirror.com.ph/2019/05/01/applying-the-financialquotient-daily/

Lusardi, A., \& Mitchell, O. (2014). The Economic Importance of Financial Literacy: Theory and Evidence. Journal of Economic Literature, 52(1), 5-44.

Lynch, J. (2011). Introduction to the Journal of Marketing Research special interdisciplinary issue on consumer financial decision making. Journal of Marketing Research, 4-8.

Mohiuddin, Z. A. (2018). Effect of Lifestyle on Consumer Decision Making: A Study of Women Consumer of Pakistan. Journal of Accounting, Business and Finance Research, 2(1), 12-15.

Mujanah, S., Ratnawati, T., \& Kusmaningtyas, A. (2019, March). The Effect of Competence, Emotional Quotient, and Financial Quotient on The Business Performance of Small and Medium Enterprises in Surabaya, Indonesia. In 16th International Symposium on Management (INSYMA 2019).

Nano, D. (2015, November). The Interrelationship between Financial Attitude, Financial Behavior and Financial Knowledge. International Journal of Business and Technology, 4(1).

Niinimaki, K. (2010). Eco-Clothing, Consumer Identity And Ideology. Sustainable Development, 18, 150-162.

Nobriyanni, A. P., \& Haryono, N. A. (2019). Faktor-faktor yang Memengaruhi Financial Management Behavior pada Keluarga TKI di Kabupaten Ponorogo. Jurnal Ilmu Manajemen , 7(3).

Paramasivan, C., \& Subramanian, T. (n.d.). Financial Management. New Delhi: New Age International Publishers.

Ratnawati, H. T., Rohmasari, F., \& Lokajaya, I. N. (2017, September). Financial Literacy And Financial Inclusion Strategy Model As Leverage Welfare 
Of Industrial Community Tourism Regency Of Gresik East Java. Jurnal Penelitian LPPM Untag Surabaya, 2(1).

Ricciardi, V. (2008). Risk: Traditional Finance versus Behavioral Finance . In F.

J. Fabozzi, The Handbook of Finance Volume 3: Valuation, Financial Modeling, and Quantitative Tools (pp. 11-38). Hoboken, NJ: John Wiley \& sons, Inc.

Robb, C. A., \& Woodyard, A. S. (2011). Financial Knowledge and Best Practice Behavior. Journal of Financial Counseling and Planning, 22(1), 60-70.

Rooij, M. V., Lusardi, A., \& R.J.M., A. (2012). Financial Literacy, Retirement Planning and Household Wealth. The Economic Journal, 122(560), 449478.

Sharma, S., \& Lal, K. (2012). Changing Consumen Behavior - A Challenge for Sustainable Business Growth. International Journal of Marketing, Financial Services E Management Research, 1(8), 149-158.

Sholz, J. (2012). Myth Busting: Living in Harmony with Nature is Less Harmonic than it Seems . Research in Consumer Behavior, 297-313.

Skals, M. V. (2020, January 29). AARHUS BSS School of Business and Social Science. (AARHUS University) Retrieved April 14, 2020, from bss.au.dk: https://econ.au.dk/research/data-and-computational-resources/researchthemes/household-finance/

Tian, K. T., Bearden, W. O., \& Hunter, G. L. (2001, June). Consumers' Need for Uniqueness: Scale Development and Validation. Journal of Consumer Research, 28(1), 50-66.

Todd, S., \& Lawson, R. (2003). Towards an understanding of frugal consumers. Australian Marketing Journa, 1(3), 8-18.

Vermeir, I., \& Verbeke, W. (2008). Sustainable food consumption among young adults in Belgium: Theory of planned behaviour and the role of confidence and values. Ecological (Tian, Bearden, \& Hunter, 2001)economics, 64(3), 542-553. Ecological Economics, 64(3), 542-553.

Vitt, L. A., Anderson, C., Kent, J., Lyter, D. M., Siegenthaler, J. K., \& Ward, J. (2000, January). Personal Finance and the Rush to Competence: Financial Literacy Education in the U.S.

Workman, J., \& Lee, S. (2011). Vanity and Public Self-Consciuousness: A Comparison of Fashion Consumen Groups and Gender. International Journal of Consumen Studies, 35(3), 307-315. 
Xiao, J. (2009). Applying behavior theories to financial behavior . In Handbook of Consumer Finance and Research (pp. 69-81).

Young, W., Hwang, K., McDonald, S., \& Oates, C. (2010). Sustainable consumption: Green consumer behaviour when purchasing products. Sustainable Development , 18(1), 20-31. 